\title{
ANALYSIS OF COMBUSTION BEHAVIOR AND PHYSICAL PROPERTIES OF WATER-DIESEL
}

\author{
Jonghan Won and Seung Wook Baek \\ Korea Advanced Institute of Science and Technology \\ 291 Daehak-ro, Yuseong-gu, Daejeon 34141, Republic of Korea
}

\begin{abstract}
Diesel has excellent fuel economy and high stability, so it has used for the fuel of transportation and power plant. However, diesel is restricted due to environmental problems from emission thus it has been studied for an increase in fuel efficiency and reduction of emission in the recent. To solve the problems, emulsion fuel, which is not only eco-friendly fuel but also an increase in fuel efficiency, has taken attention in the world. Emulsion fuel can change the viscosity characteristics as well as combustion characteristics according to the mixing method, mixing time and temperature. The combustion characteristics study of single droplet, which can remove remained gases and heat, is one of main study for understanding complicated combustion. In this study, optimum concentration (Water/Diesel=1.0) for stability of water-diesel emulsion was founded by analyzing various concentrations, mixing time and characteristics of viscosity measurement. Based on optimum concentration of emulsion, the combustion characteristics research of single emulsion droplet was experimentally carried out under high ambient temperature $\left(400-700^{\circ} \mathrm{C}\right)$ and pressure $(1-15$ bar $)$ conditions.
\end{abstract}

\section{KEYWORDS}

Emulsion, Droplet, Combustion, Micro-explosion, Viscosity

\section{INTRODUCTION}

Diesel has excellent fuel economy and high stability, so it has used as the fuel of transportation and power plant. However, since diesel is limited due to the environmental problems caused by emission, it has been studied for an increase in fuel efficiency and reduction of emission in the recent. As part of these researches, the solution studies have been conducted by replacing biodiesel or mixing additives. Among them, water-in-oil emulsion fuel, which is not only eco-friendly fuel but also an increase in fuel efficiency, has taken attention in the world. In particular, emulsion fuel can reduce NOx emission and meet the strict emission regulation [Selim, M. and Ghannam, M., 2009; Zhang G. et al, 2017]. In the case of NOx production, the main reason is thermal NOx, in which atmospheric nitrogen gas is dissociated by high heat and reacts with oxygen. During emulsion combustion, the water vapor was trapped in an emulsion droplet due to the difference in boiling point with water and oil, and micro-explosion occurred when water vapor instantly emerged. In this phenomenon, the liquid droplet was well atomized thus it could be almost close to complete combustion, which made the emission reduction and improvement of fuel efficiency. In previous studies, NOx and PM could be reduced by $40 \%$ and $35 \%$ respectively without change in engine performance. To achieve this ideal effects, the researches on ratio of water-diesel, size of distributed droplets, viscosity, proper mixing method, and etc., should be investigated more intensely [Kichatov B. et al, 2017].

Emulsion fuel can change in physical properties as well as combustion characteristics depending on the mixing method, mixing time and storage temperature. The stability, fluidity, and uniformity of the mixture can be distinguished by physical properties [Ithnin A. et al, 2015]. The viscosity is an important parameter among physical properties in the injection system because low viscosity fuel well atomized in the injection system due to better fluidity hence excellent effects could be expected in fuel consumption and emission reduction.

A droplet combustion study is fundamental research for spray combustion and it observes the characteristics of pure fuel droplet without the interaction of other droplets and remained heat. Research on isolated droplet is necessary process for complicated combustion and sometimes it is very important at some cases that can be fully understood by its characteristics alone. Therefore, many studies have been investigated for analysis of characteristics of single droplet combustion [Ghassemi H. et al, 2006]. 
In this study, emulsion stability and viscosity were observed at various temperature conditions. Additionally, combustion characteristics of a single emulsion droplet were analysed under high ambient temperature and pressure conditions.

\section{METHODOLOGY}

\subsection{Emulsion Synthesis}

In emulsion synthesis research, water and diesel are immiscible chemicals thus special mixing method are required such as high pressure method, impeller, ultra-sonication. Especially using the ultra-sonication (VCX-130, USA) can easily make the emulsion fuel in a short time. Through this method, emulsion fuels were produced under five conditions by changing the mass ratio of water and diesel. Emulsion fuels were produced each total $10 \mathrm{~g}$ and mass ratios were Water/Diesel(W/D)=0.3, 0.6, 1.0, 1.2 and 1.5 as shown in Figure 1. If water content was higher than diesel, i.e. more than $\mathrm{W} / \mathrm{D}=1.0$ condition, emulsion could be perfectly mixed but they separated to the 3 phases as emulsion, water, and diesel within 5 hours. Therefore, surfactant (emulsifier) was essential to make a complete and stable emulsion fuel. Surfactant had to be added to make stable emulsions that could be stored for long period. Surfactants can be classified as 0 to 20 HLB (Hydrophilic Lipophilic Balance). Surfactants as 4 to 6 are commonly used for water-in-oil emulsion and surfactants as 8 to 18 are used for oil-in-water emulsion therefore surfactant of proper HLB should be added [Genot C. et al, 2013]. Also surfactants have synergistic effects when mixed with two different surfactants to give a better effect. When two surfactants are mixed, the molecules of surfactants constitute the micelle structure at the appropriate concentration then mixing ability improves as physicochemical property is changed [Noor El-Din M. et al, 2013]. In this study, Span80(HLB 4.3) and Tween20(HLB 16.7) were used as surfactants. The HLB value of mixed surfactant was calculated by mass ratio from equation 1 [Xie, F. and Brooks, B., 2005].

$$
\mathrm{HLB}_{\mathrm{ST}}=\mathrm{f}_{\mathrm{T}} \times \mathrm{HLB}_{\mathrm{T}}+\left(1-\mathrm{f}_{\mathrm{T}}\right) \times \mathrm{HLB}_{\mathrm{S}}
$$

Where $f_{T}$ is mass fraction of Tween20, T and S are abbreviation of Tween20, Span80 respectively. Mixed surfactants were produced Mixed surfactants were produced from HLB 8 to HLB 16 with a stirrer at $1500 \mathrm{rpm}$ in a total of 10 minutes with reference to a previous study [Liang X. et al, 2018] and the mixed surfactant of HLB 14 showed the best effect. Figure 2 shows the prepared emulsions along water-diesel mass ratios containing 0.2 wt.\% surfactant. Despite containing mixed surfactant, water and diesel were difficult to mix at low water content of $\mathrm{W} / \mathrm{D}=0.3$ and 0.6 mass ratios, but emulsions of more than $\mathrm{W} / \mathrm{D}=1.0$ mass ratio extended the stable time to more 1 day.

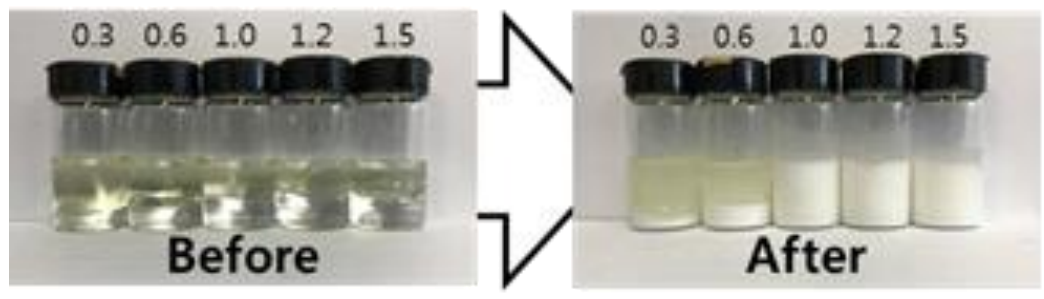

Figure 1. Emulsions Synthesis Result of at Each Water-Diesel Ratio 


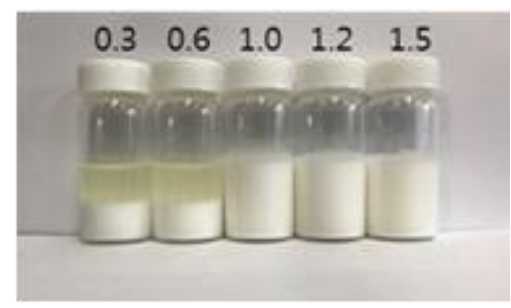

Figure 2. Emulsions Synthesis Result of at Each Water-Diesel Ratio Containing the 0.2 wt.\% Mixed Surfactant

\subsection{Viscosity Measurement Condition}

The viscosity was measured at $15^{\circ} \mathrm{C}, 30^{\circ} \mathrm{C}$ and $60^{\circ} \mathrm{C}$ which is the temperature range of freezing point $\left(0^{\circ} \mathrm{C}\right)$ and boiling point $\left(100^{\circ} \mathrm{C}\right)$ of water at 1 bar. The viscosity is an important parameter in the injection system because low viscosity fuel is well atomized due to better fluidity hence excellent effects could be expected on fuel consumption and emission reduction. The measuring apparatus was the rheometer (HAAKE RheoStress 6000 , Germany), and measured the absolute (dynamic) viscosity as the shear rate rise.

\subsection{Combustion Experiment}

Figure 3 is the schematic diagram of constant combustion chamber which already used in previous study [Won J. et al, 2018]. The electric furnace inside the chamber used a heating coil surrounded by a ceramic shield to maintain the temperature uniformly in the range of $400^{\circ} \mathrm{C}$ to $700^{\circ} \mathrm{C}$ and protect the radiation effect. Dry air controlled the ambient pressure and purged the chamber after finishing every experiment. When the temperature inside the electric furnace reached the target temperature, an emulsion droplet $(750 \pm 100 \mu \mathrm{m})$ was suspended at the tip of k-type thermocouple using a syringe consisting of a $50 \mu \mathrm{m}$ of $\mathrm{Al}-\mathrm{Cr}$ wires. The electric furnace fell down along the two guides to the thermocouple then a droplet instantly exposed to high ambient temperature condition. The evaporation and combustion process of an emulsion droplet were recorded at $200 \mathrm{fps}$ with high speed camera. Ambient temperature condition was controlled at $100^{\circ} \mathrm{C}$ interval in range of $400^{\circ} \mathrm{C}$ to $700^{\circ} \mathrm{C}$. Ambient pressure condition controlled in range of 1 bar to 15 bar at 5 bar interval. Experiment repeatedly carried out at least five times.

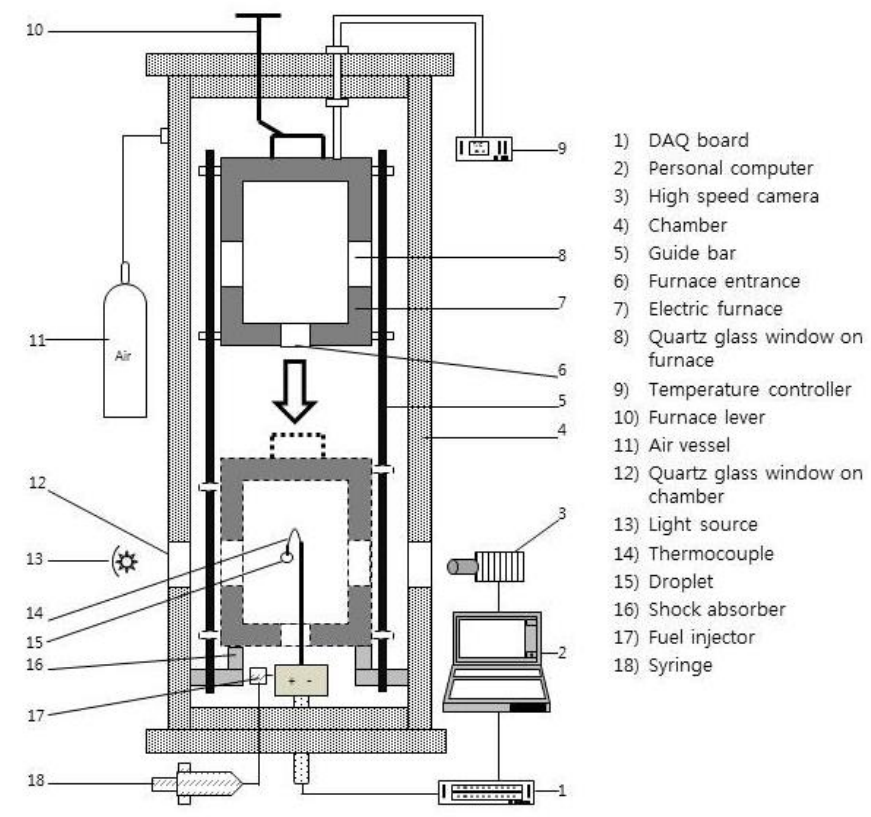

Figure 3. Schematic Diagram of Constant Combustion Chamber 


\section{RESULTS AND DISCUSSION}

\subsection{Viscosity}

Figure 4 shows the viscosity along the temperature rise at each water-diesel concentration of emulsions. The sample was extracted $2 \mathrm{~mL}$ at middle of emulsion for measurement. Emulsions of W/D=0.3, 0.6 separated into two phases, and the viscosity was measured at upper and lower phases. The results show that all emulsion viscosity values were higher than diesel, and the viscosity of $\mathrm{W} / \mathrm{D}=1.0$ emulsion was higher than any other case. The effective concentration of dispersed droplet during shear rate increased hence the viscosity of $\mathrm{W} / \mathrm{D}=1.0$ emulsion was the highest and the viscosity of $\mathrm{W} / \mathrm{D}=1.5$ emulsion has lower value due to relatively low amount of dispersed droplets. In general, the viscosity reduced to exponential curve as an increase in temperature and emulsions except for $\mathrm{W} / \mathrm{D}=1.0$ followed this phenomenon. However, $\mathrm{W} / \mathrm{D}=1.0$ emulsion didn't follow due to fast coalescence with increasing temperature. As the temperature rise, the interfacial film weakened and easily broke hence droplets could be easy coalescence. Because W/D=1.0 emulsion had relatively large amount of dispersed droplets, coalescence occurred more easily than other cases so the viscosity sharply decreased and separated into water-diesel phases as the temperature rise.

Figure 5 is the viscosity change of $\mathrm{W} / \mathrm{D}=1.0$ emulsion with $0.2 \mathrm{wt} . \%$ surfactant (HLB 14). It was shown that viscosity was independent of mixing time hence it was stable emulsion. However, the viscosity values increased about 1.5 times as compared with $\mathrm{W} / \mathrm{D}=1.0$ emulsion without surfactant. Emulsion containing large amount of water content was liable to be mixed but since the amount of diesel was reduced, the combustion efficiency decreased or combustion may not occur. Therefore, emulsion of $\mathrm{W} / \mathrm{D}=1.0$ mass ratio containing 0.2 wt.\% surfactant of HLB 14 was optimum condition, it was used for combustion experiment.

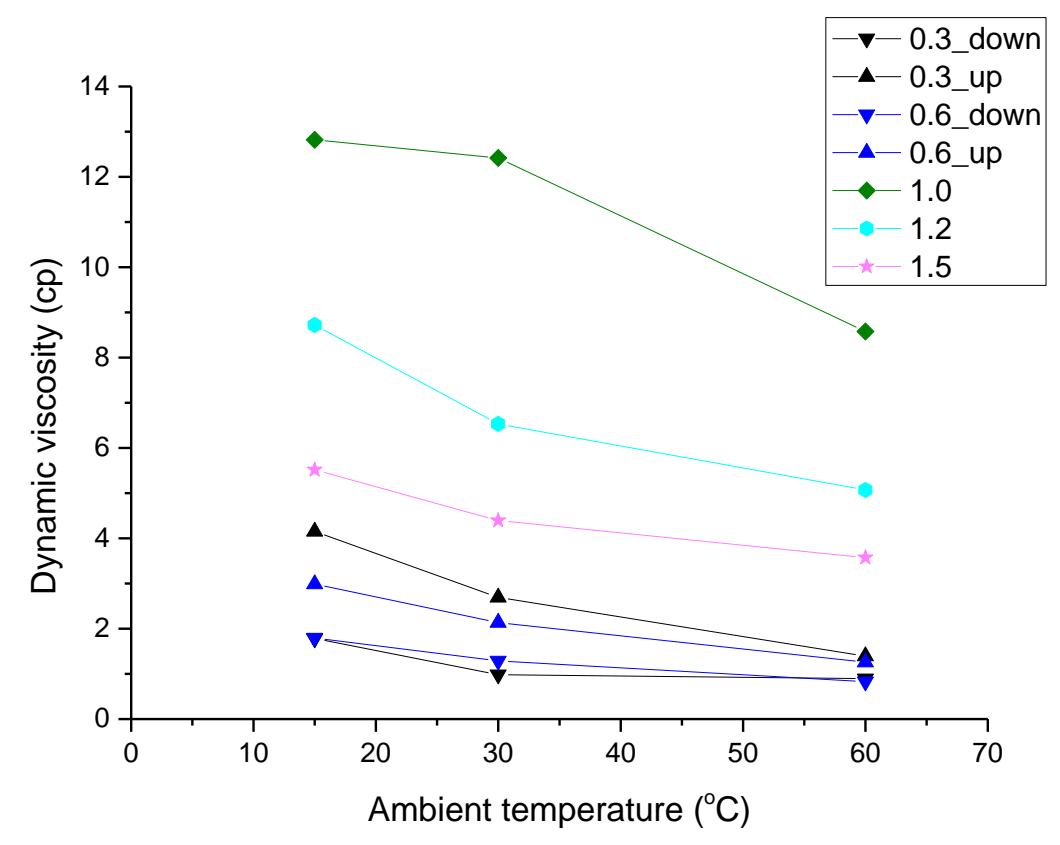

Figure 4. Viscosity change at each Water-Diesel Concentration as Temperature Rise 


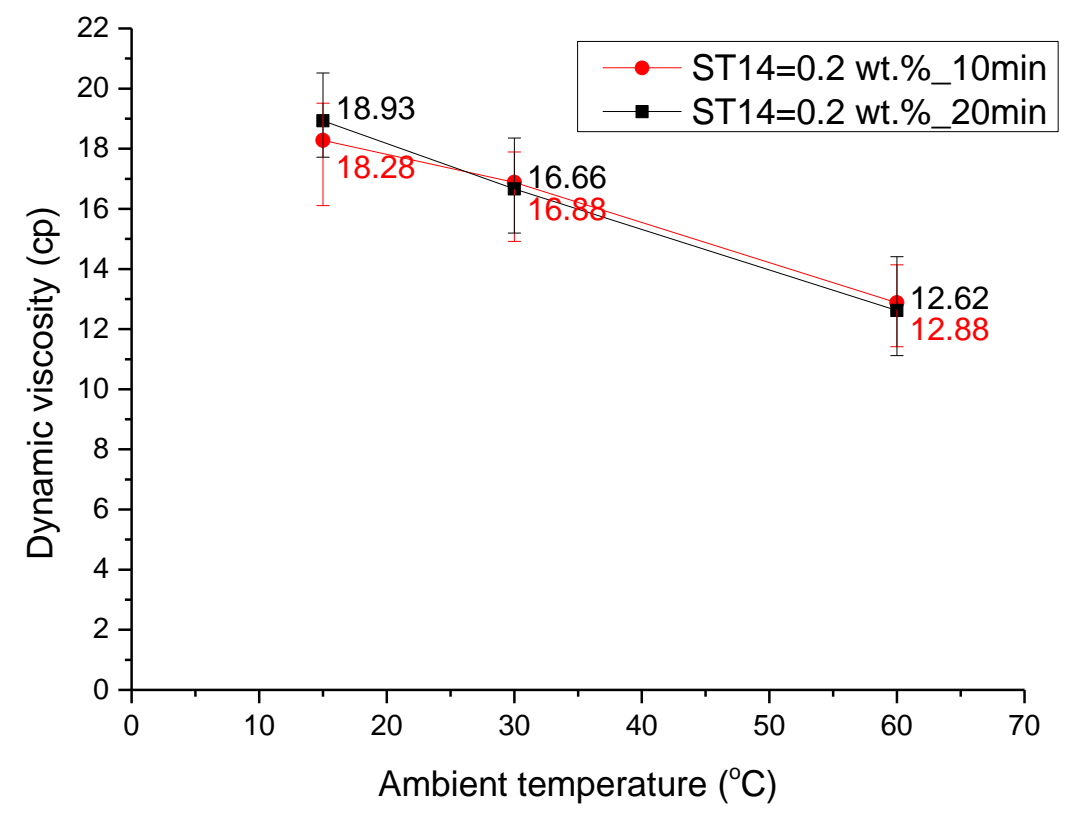

Figure 5. Viscosity change of Emulsion Containing Surfactant along Different Mixing Time

\subsection{Emulsion Droplet Combustion}

Emulsion droplet didn't ignite because of strong micro-explosion at 1 bar ambient pressure condition. Prior to ignition, atomized droplets caused by micro-explosion emerged from a main droplet and a main droplet detached from a tip of k-type thermocouple therefore high speed camera couldn't capture the combustion process. When ambient pressure raised, the ignition delay of diesel decreased at below $500^{\circ} \mathrm{C}$ ambient temperature condition but increased at above $600^{\circ} \mathrm{C}$ ambient temperature condition. On the other hand, the ignition delay of emulsion decreased with increasing ambient pressure at all temperature conditions. The first reason was that the specific heat of water is higher than diesel, and the second reason was that micro-explosion hindered the ignition at low ambient temperature condition but it caused fast ignition at high ambient temperature condition.

Total droplet lifetime was the sum of ignition delay and flame lifetime in fig. 6. Total droplet life time of emulsion was higher than diesel in all conditions because of long ignition delay. However, total droplet lifetime of emulsion became sharply short at low ambient pressure and high ambient temperature condition due to micro-explosion effect. If the ignition of an emulsion droplet was possible under $600^{\circ} \mathrm{C}$ ambient temperature and lower than 5 bar ambient pressure, total droplet lifetime of emulsion would be shorter than diesel case. 


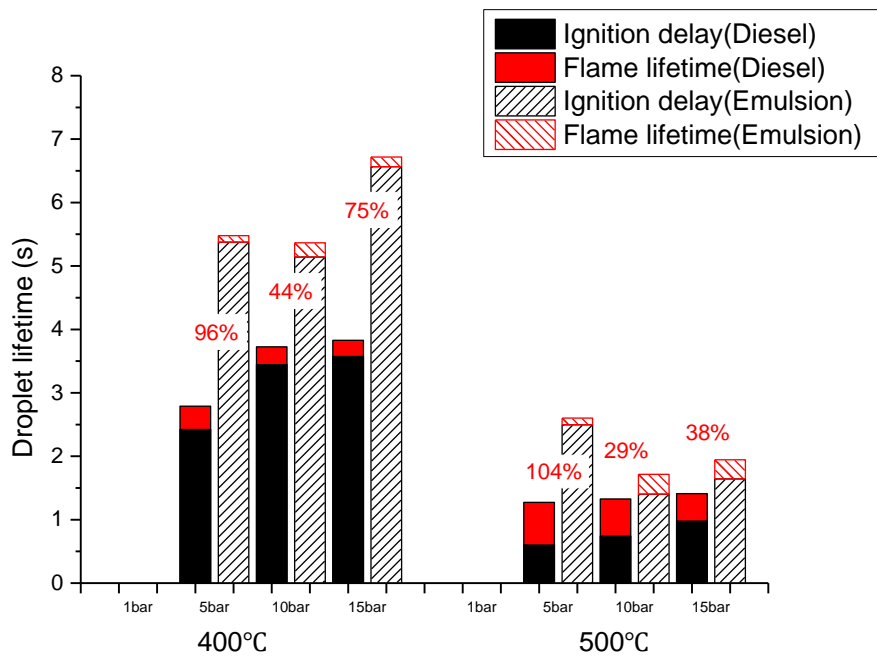

(a)

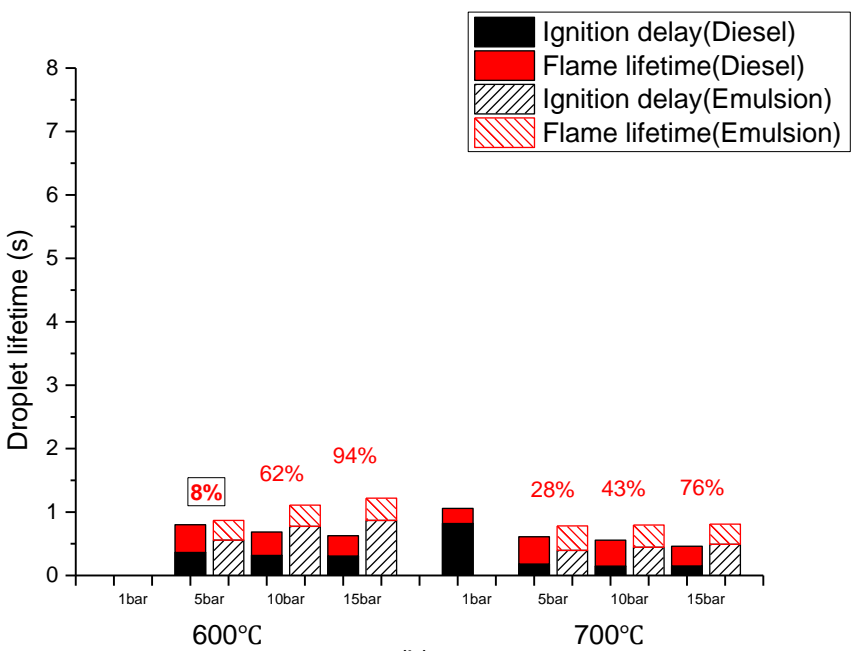

(b)

Figure 6. Total Droplet Life Time at: (a) $400^{\circ} \mathrm{C}, 500^{\circ} \mathrm{C}$ and (b) $600^{\circ} \mathrm{C}, 700^{\circ} \mathrm{C}$ of Ambient Temperature

\section{CONCLUSION}

In this study, the characteristics of emulsion viscosity were analyzed at various temperature conditions. Additionally, autoignition and combustion characteristics of single emulsion droplet under various ambient temperature and pressure conditions were experimentally examined. The results are summarized as below.

1. The viscosity of $\mathrm{W} / \mathrm{D}=1.0$ emulsion was the highest than any other concentration because dispersed droplets increased the effective concentration as shear rate rise. When adding $0.2 \mathrm{wt} . \%$ of mixed surfactant (HLB 14), emulsion viscosity had uniform values independent on mixing time. Consequently, W/D=1.0 emulsion containing $0.2 \mathrm{wt}$ \% surfactant was optimum concentration for using the fuel.

2. Ignition delay of a diesel droplet increased as ambient pressure rise at below $500^{\circ} \mathrm{C}$ ambient temperature however, it decreased at above $600^{\circ} \mathrm{C}$ ambient temperature. Ignition delay of an emulsion droplet increased as ambient pressure rise at above $600^{\circ} \mathrm{C}$ ambient temperature due to the effect on micro-explosion. 
3. Total droplet lifetime of an emulsion droplet was higher than a diesel droplet at all ambient condition. But it was possibility that total droplet lifetime of an emulsion droplet could be shorter than a diesel droplet if the ignition condition was found at $600^{\circ} \mathrm{C}$ ambient temperature and lower than 5 bar ambient pressure.

Based on the results, the viscosity characteristics of emulsion were analyzed and emulsion fuel found the potential to replace diesel.

\section{REFERENCES}

Genot C. et al, 2013. 5-Stabilization of omega-3 oils and enriched foods using emulsifiers. Food Enrichment with Omega3 Fatty Acids, pp 150-193.

Ghassemi H. et al, 2006. EXPERIMENTAL STUDY ON EVAPORATION OF KEROSENE DROPLETS AT ELEVATED PRESSURES AND TEMPERATURES. Combust. Sci. and Tech., Vol. 178, pp 1669-1684.

Ithnin A. et al, 2015. Combustion performance and emission analysis of diesel engine fuelled with water-in-diesel emulsion fuel made from low-grade diesel fuel. Energy Conversion and Management, Vol. 90, pp 375-382.

Kichatov B. et al, 2017. Experimental study of foamed emulsion combustion: Influence of solid microparticles, glycerol and surfactant. Fuel Processing Technology, Vol. 166, pp 77-85.

Liang X. et al, 2018. Investigation of oil-in-water emulsion stability with relevant interfacial characteristics simulated by dissipative particles dynamics. Colloids and Surfaces A: Physicochemical and Engineering Aspects, Vol. 546, pp 107-114.

Noor El-Din M. et al, 2013. Water-in diesel fuel nanoemulsions: Preparation, stability, and physical properties. Egyptian Journal of Petroleum, Vol. 22, pp 517-530.

Selim, M. and Ghannam, M., 2009. Combustion study of stabilized water-in-diesel emulsion. Energy Sources Part A, Vol. 32, pp 256-274.

Won J. et al, 2018. Autoignition and combustion behavior of emulsion droplet under elevated temperature and pressure conditions. Energy, Vol. 163, pp 800-810.

Xie, F. and Brooks, B., 2005. Phase behaviour of a non-ionic surfactant-polymeric solution-water system during the phase inversion process. Colloids and Surfaces A: Physicochemical and Engineering Aspects, Vol. 252, No. 1, pp 27-32.

Zhang G. et al, 2017. Influence of side-chain structure of polycarboxylate dispersant on the performance of coal water slurry. Fuel processing technology, Vol. 161, pp 1-7. 